\title{
Research on Application of New Materials and Technology of Decoration Design
}

\author{
Ni Ming \\ Suqian College,Suqian,223800,P.R.CHINA \\ nimingnm@126.com
}

Keywords: Decorative Design, New Materials Technology, Application

\begin{abstract}
Development of the construction industry, driven by the progress of decoration industry, building materials technology applications at the same time gradually developed. As the market's prosperity and people's diverse needs, new materials, new technology and new technology, innovation and research become a trend. Operation is to be noted decoration new materials, new technology has its own characteristics, should be specific to distinguish different processes and materials, the application process should seek different ways, using different operating procedures according to different technological principles. Only through continuous research and development of new technologies, new materials, new technology, in order to promote the construction industry entered a rapid and sound development track, and promote healthy and stable development of social economy. In the current context of diversified development, the emergence of new materials, new technology, it is possible to meet more of the people's diverse needs.
\end{abstract}

\section{Theoretical Introduction of Decoration New Materials Technology}

New materials refer to recent developments in some of the materials being developed or superior performance than traditional materials more excellent properties of a class of materials. New materials, new technology is in accordance with the will of the people, by physics, chemistry, materials design, materials processing, and a series of trials evaluating the research process, summarize create technology to meet the needs of the new material. Continuous emergence of new processes, technologies and materials the construction experience into theory and application of these theories into the construction program to practice.

Decorative materials have its own characteristics, but the nature of the new decorative material has a more important feature. New material advantage in the energy saving aspects of the more obvious, as people decorative material properties and structure of research and understanding of the basic nature of the decorative material has been mastered, through technical means and new technology, new technology, in an increasingly mature under the guidance of modern materials design theory, it can create more and better performance of new decorative materials. Summary, in addition to the fine nature of the nature of traditional materials, new decorative materials also have to install labor-saving, energy-saving and environmental protection ${ }^{[1]}$.

Application of new materials is a material having advantages over traditional materials. Design and manufacture of new materials is the use of more advanced production technology, and also is the result of years of research and development from the scrutiny of the material, the aesthetic is a strong advantage. The first is visual, research and development of new materials and technology to make it very prominent in the visual beauty; followed by touch, new material is based on having a strong touch feel. An important part of the new material and technology is both contemporary decoration industry but it is also an important breakthrough in the development of decoration industry, research and development and use of innovation and application of new technologies and new materials are crucial, as well as materials for construction research and development unit are very important. 


\section{Characteristics of Decoration Engineering New Materials Technology}

In the 21st century, new materials, material technology breakthrough will enable a large extent material goods intelligent, multi-functional, environmental protection, composite, low cost, long life and be customized by the user. These products will accelerate revolutionary advances in information industry and biotechnology, it is possible to manufacturing, services and people's lifestyles have a significant affect. Overall, the development of new materials moving from revolution to reform, development cycle is shortened, and innovation has become the soul of the new material development. New materials, new technology plays its characteristic nature in today's construction projects, mainly as follows ${ }^{[2]}$. Fig. 1 shows characteristics of decoration engineering new materials technology.

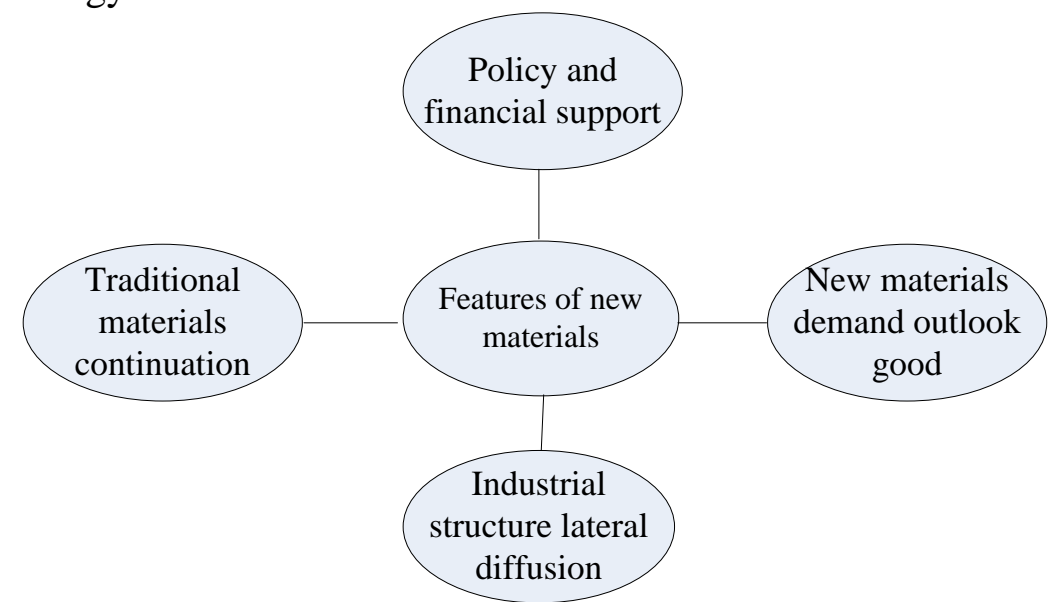

Fig. 1.The characteristics of decoration engineering new materials technology

New materials, new technology is both a continuation of the traditional materials and technology, but also the development of new materials to promote new technologies to improve conventional materials and processes to achieve the goal. With the development of high-tech, new materials and combine traditional materials industries increasingly close, the industrial structure have shown a lateral diffusion characteristics. Traditional materials industry forward new materials industry is gradually expanding, many famous and new materials production and processing enterprises take advantage of early accumulation of mass-production technology at the same time in the world, productivity and adequate monetary funds into research and development and production of new materials for processing. This is a historical necessity for the regularity development.

Based on the construction of prosperous development of the market, the market demand for new materials is extremely strong, while also forming a dramatic expansion of industrial scale, with the rapid development of social scientific and technological progress and emerging industries, the type and quantity of new material requirements are greatly increased the market demand for new materials is very promising. New materials development and coordination of resources, ecological environment and much attention, in the context of the rapid development of the world economy, countries currently have to deal with - the huge pressure on resources, environment and population, the world continues to increase intensity of green materials and environmental research and development of materials related areas, the government through policy, funding have given the greatest support $^{[3]}$.

\section{Application Principles of New Materials and Technology}

Indoor environment is an important part of human living environment, green design focuses on the ecological balance of the relationship between man and nature, every decision in the design process, the detailed decision should fully take into account the environmental benefits and minimize damage to the environment. Interior design, the core of which is the use of non-toxic, non-polluting, 
energy-saving, antibacterial not only harmful to human health, but also beneficial to human health, environmental protection, health-based decoration, decoration materials. Performance and application designers in interior design material should follow the following basic principles ${ }^{[4]}$.

It refers to the so-called harmonious interdependence of various people with their living environment, the coordinated development of the relations. Interior design subject is a human construct interior space division function, material use shall meet all the requirements of the people, creating a having functional and comfortable facilities, beautiful space visual image, a reasonable temperature and humidity ideal living environment. All this can only be achieved through scientific and rational use of the material in order. Substance main function is to meet people's basic needs, to facilitate people's daily lives. Mental function mainly refers to the use of modern technology to the material texture, color, converted into a concise, rhythm, dignified, beautiful and other spatial modeling, to create a harmonious, cozy, comfortable space, gives people a better fantasy to imagine the psychological experience people indulge in the pleasure of feeling among the aesthetic enjoyment.

Combined with the structural characteristics of the room, well-designed, the different grades of materials ingenious combination, give full play to its different textures, colors, performance advantages, we can achieve both economic and practical landscaping principles. When designing material selection must consider not only the initial cost of renovation, but also consider the cost, do you want to spend the least money and strive to achieve the best results. Because different people in different sectors of the living environment, life experience, personality traits, hobbies, etc., their own living space environment will inevitably have different requirements and aesthetic taste, reflecting its need for a personalized living space. In particular the design process, personalized modeling materials, techniques with color, texture processing can create a people with distinct personality characteristics within the home environment.

\section{Applications of Decorative New Technologies}

In order to promote decorative construction industry, it is bound to the application of new technology, new technology and new materials, which have mastered the environmental, safety and efficient technologies and products in all aspects, must take precedence. Decorative construction relationship, so the application of new technologies to beautify the environment is very important. In order to strengthen the construction and decoration of new technologies application, we need to start from the following aspects ${ }^{[5]}$. Fig.2 shows applications of decorative new technologies.

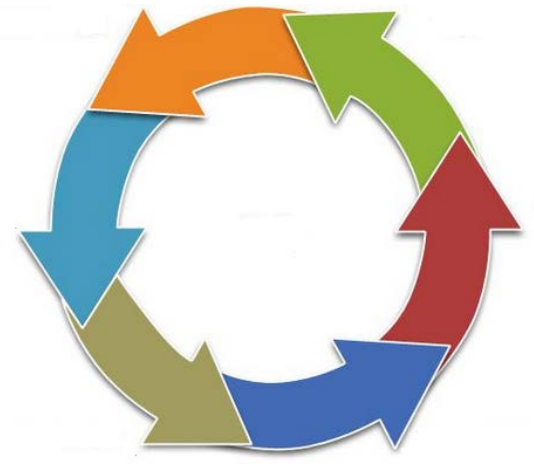

Fig. 2.The applications of decorative new technologies

The decorative construction technology involved, should gather relevant information in accordance with the building materials, chemicals, metal and textile categories for archiving, but also further refined in several categories, such as the chemical industry and can be divided into waterproof , fire and anti-corrosion materials, these materials were reserves file pocket, once the need for future search and find more convenient. Further development on the basis of traditional decor, resulting in a modern decoration technology, which have been greatly improved, using different techniques, materials, technology is bound to bring new change and renovation, nanotechnology and appear further accelerate the decorative paint vitality need to make decorative 
paint products used in the epoch-making development occurred, is bound to promote the decoration construction process and technology changes.

Whether it is design or construction personnel must have high quality requirements, but also have comprehensive professional requirements. Technical management of building decoration works construction companies need to have a high level of professional and technical personnel and management personnel, and management personnel must have a high level of expertise and management of compound talents. This requires construction companies to be the selection of suitable personnel within the enterprise-the-job training, business transport complex talent can improve the management level of construction technology enterprises and market competitiveness through job training.

\section{Conclusions}

Applications decoration works of new materials, new technology is very broad, ranging from the application of new materials, new technology has become increasingly open to expansion, new materials, new technology applications in all the professional construction industry in. Used in the decoration works in a variety of new materials, new technology and new technology gradually become the trend of the development of the construction industry, a wide range of application of new materials, new technology, prospects, and become in the use of project details under these skills materials more perfect, environmentally friendly and beautiful. Applications and Prospects of new decoration materials, new technology is very broad. Since the decoration of new materials, new technology has its own characteristics, the application of new materials and technology in the decoration works, they need to be treated differently. The method for the application of new materials, new decoration process should be based on more specific can explore the different projects with different characteristics, and their application methods must also be different.

\section{References}

[1] Li Feng. Architecture interior decoration materials. Machinery Industry Press, 2008, 3.

[2] Architectural Creation magazine commitment compiled. National Grand Theatre designed volume. Tianjin University Press, 2008, 8.

[3] Jiang Weiping, Using new Chinese style modern home design [J] beauty and age, 2009 (9): 74-77.

[4] Lou Baohong, Shiyong Yao, On the innovation of design and decoration [J]. Science and Technology Innovation Herald, 2009, (10).

[5] Nikolaus Pevsner. The Sources of Architecture and design [M]. Thamers and Hudson Ltd.,London. 2015:32-33. 